\title{
Antropologia e performance. Terra de ninguém ou terra de todos?
}

Sílvia Raposo - Faculdade de Ciências Sociais e Humanas, Universidade Nova de Lisboa - Centro em Rede de Investigação em Antropologia ${ }^{1}$

DOI: http://dx.doi.org/10.5565/rev/periferia.590

\section{Resumen}

O presente artigo destina-se à apresentação e discussão crítica do performative turn nos Estudos da Performance e do ritual, procurando compreender as relações que a performance pode estabelecer com o político e de forma se pode pensar a performance como modo de documentar/analisar o mundo social. Para tal procurase reerguer um edifício teórico complexo tendo em vista consagrar os Estudos da Performance como um campo que foge a uma focagem definitiva e se define como uma anti-disciplina.

Palabras clave: Antropologia; Performance; Estudos da Performance.

\section{Abstract. Anthropology and Performance. Nobody's land or everybody's land?}

This article aims to present and debate critically the performative turn in Performance Studies and ritual, trying to understand the relations that performance can establish with the political so that one can think of performance as a way of documenting / analyzing the social world. In order to do so, a theoretical complex is needed in order to establish Performance Studies as a field that escapes a definitive focus and defines itself as an anti-discipline.

Keywords: Anthropology; Performance; Performance Studies.

\section{Introdução:}

O presente artigo, Antropologia e performance. Terra de ninguém ou terra de todos?, procura apresentar e criticar as principais correntes teóricas presentes nos Estudos da Performance, sob a lente da antropologia, face a duas questões - Qual a relação entre performance e política? De que modo se pode pensar a performance como forma de documentar/analisar o mundo social? -, procurando reerguer um

\footnotetext{
${ }^{1}$ Enviar correspondencia a: Sílvia Raposo silvia961993@gmail.com
} 
edifício teórico complexo, composto por diversas perspectivas, uma vez que o campo da antropologia da performance foge a uma focagem definitiva, constituindo-se como uma «anti-disciplina». Analisa-se o modo como se dá o "performative turn" nos estudos antropológicos do ritual, tendo em vista estabelecer uma relação entre performance, política e resistência. Para tal, partindo dos Estudos da Performance, evidencia-se uma lente teórica que sustenta um olhar sobre a sociedade como numa «sociedade do espectáculo» marcada por uma performance do mundo social em que toda a actividade humana é performativa, inclusive os recursos linguísticos, e as relações sociais são mediadas por performances que procuram as suas manifestações no campo da «fachada» (Schechner, 2006; Goffman, 2011) e contribuem para legitimar as estruturas do poder através de uma «teatrocracia» que sustenta o fosso entre governantes e governados (Balandier, 1982). Uma sociedade onde irrompem episódios de conflito e de tensão - «dramas sociais» (incluindo fontes de forma estética) -, que se apresentam como um «metateatro», um espaço simbólico de representação da realidade social que permite aos actores sociais estarem à «margem» da sociedade e recorre à inversão de papéis, tornando-se um espaço simultaneamente reflexivo onde as estruturas de experiência grupal são copiadas, desmembradas e resignificadas (Turner, 1986) e onde se denuncia a forte relação entre performance, política e resistência.

\section{Qual a relação entre performance e política?}

A cultura é um movimiento do espírito que vai do vazio às formas, e que das formas regressa ao vazio, ao vazio como para a norte. Ser culto é queimar formas, queimá-las a fim de se atingir a vida. É aprender a manter-se reto dentro do incesante movimiento das formas que vão sendo sucesivamente destruídas (Quilici, 2004: 201).

"No Performance Land?" entre a teoria e a prática dá nome ao primeiro encontro internacional sobre performance realizado em Portugal, que decorreu em Lisboa, de 15 a 27 de Abril de 2011. O encontro foi organizado pelo CRIA em colaboração com a Culturgest, tendo como objectivo primordial interrogar o lugar da performance na contemporaneidade, bem como explorar as articulações entre a Antropologia e os 
Performance Studies. Quero, portanto, iniciar a minha reflexão a partir da questão que abre o título deste encontro: "No Performance Land?". Que terreno indefinido será este? Tal interpelação remete desde logo para um campo de estudos que foge a uma focagem definitiva e se caracteriza por uma permanente redefinição, o que me impele a interrogar e explorar o que leva a que os teóricos contemporâneos classifiquem o território da performance como uma «terra de ninguém?». O que quererão transmitir através desta ausência de sujeito? Ou falaremos antes de um sujeito pluralizado?

Designando o termo «terra de ninguém» um território não ocupado ou que, em disputa, se neutraliza, o que pretendo compreender é o motivo pelo qual o território da performance se escuda nesta neutralidade. É certo que o campo da antropologia da performance é possível de ser entendido, nas palavras de Geertz, como "um manuscrito estranho e desbotado, cheio de elipses, incoerências, emendas suspeitas e comentários tendenciosos" (Geertz apud Dawsey, 2007: 531), terreno transdisciplinar que se constitui quase como uma «anti-disciplina». Mas, de acordo com Victor Turner, "os lugares onde um texto se desmancha podem ser os mais fecundos" (Dawsey, 2007: 531). E, de certo modo, foi este carácter subversivo de um campo de estudos que se consagra como liminar o que me atraiu no território da performance. Vi neste manuscrito desbotado um campo por excelência onde poderiam ter lugar as minhas interrogações e ilações politicamente engajadas, bem como a minha incessante procura por uma antropologia livre dos «cães de guarda» Bourdieusianos (Bourdieu, 1989).

Deste modo, constituindo-se a performance como um campo interterritorial e transdisciplinar de reflexão controversa, e entendido, por um conjunto de antropólogos que procuram implementar os Estudos da Performance em Portugal, como uma espécie de baldio que promove uma abordagem interdisciplinar, teóricoprática e politicamente comprometida, a primeira questão que levanto é se esta «terra de ninguém» de que nos falam os teóricos da antropologia da performance não será antes uma «terra de todos»? De que modo se dá o "performative turn" nos estudos antropológicos do ritual? Que desenvolvimentos recentes se deram nesta área de estudos? De que forma a experimentação de processos criativos de intervenção performativa serve para repensar o conhecimento antropológico e renovar as abordagens etnográficas? E que muros este campo de estudos nos 
permite derrubar ao nível das ferramentas antropológicas e da transdisciplinaridade na linguagem antropológica? Que ligações se podem estabelecer entre a expressão artística ou performativa e o conhecimento científico, ou de que modo o conhecimento científico pode integrar o processo de construção performativa? Que viragem é esta ao nível dos estudos da performance na contemporaneidade que procura cada vez mais articular o conhecimento antropológico com experimentações artísticas? Comecemos por procurar as respostas através desta categoria indefinida que é a «performance» ...

\section{De que modo se pode pensar a performance como forma de documentar/analisar o mundo social?}

A década de 1970 vive o apogeu da arte conceptual numa demanda por novos ideais artísticos e, reclamando uma arte que não se destine à mercantilização, a performance foi uma das expressões artísticas que traduzia essa ideologia revolucionária. Reconhecida como uma arma contra os convencionalismos da arte estabelecida, e procurando defender uma arte «das ideias» em detrimento de uma arte «do produto», a performance adquire, nesta época, o seu reconhecimento enquanto expressão artística autónoma (Goldberg, 2007). Vivendo o seu apogeu, a performance é introduzida nos programas de ensino das escolas de arte, fundam-se revistas especializadas, e emergem os mais variados espaços dedicados a esta arte (museus, festivais, galerias de arte, etc.). É precisamente nesta década que, procurando questionar a natureza da arte e explicar a importância da performance no desenvolvimento da actividade artística do séc. XX, Roselee Goldberg publica a primeira história da performance. Em $A$ arte da performance - do futurismo ao presente (2008 [1979]), a autora define a performance como uma expressão artística feita ao vivo que serve para "escandalizar os espectadores, obrigando-os a reavaliar os seus conceitos de arte e a sua relação com a cultura " (Goldberg, 2007: 8-9).

Devido a essa postura radical, a performance agiu como o grande catalisador artístico na história da arte do séc. XX, servindo para demolir categorias e redirecionar práticas artísticas sempre que determinada escola - o cubismo, minimalismo ou a até mesmo a arte conceptual - parecesse chegar a um impasse. Embora, a maioria da produção histórica e literária que se debruça sobre as vanguardas artísticas tenha sido monopolizada em torno da obra dos futuristas, 
construtivistas, dadaístas e surrealistas que foi produzida em cada um desses respetivos períodos, a verdade é que foi na performance que esses movimentos encontraram a sua origem. Assim, a performance, de acordo com Goldberg, tem sempre uma base anárquica e desde cedo se assumiu enquanto uma vanguarda da vanguarda (Goldberg, 2007).

Posto isto, pela sua maleabilidade e indeterminação, sendo uma expressão artística de infinitas variáveis praticada por artistas "insatisfeitos com as limitações das formas mais estabelecidas" (Goldberg, 2007: 10), a performance dificulta uma definição que extravase a simples afirmação de que se trata de "uma arte feita ao vivo pelos artistas" (Goldberg, 2007: 10). E à medida que esta arte anarquista ainda indefinida foi contaminando o «mundo», extravasando a Europa e os Estados Unidos, e se foi tornando também o meio de expressão selecionado para a articulação da «diferença» nos discursos sobre o multiculturalismo e a globalização, deu-se uma viragem ao nível académico, que passa a reconhecer a relevância da arte da performance nos estudos culturais, nomeadamente na filosofia, arquitetura, linguística ou antropologia, procurando desenvolver linguagens teóricas e abordagens de análise ao campo da performance (Goldberg, 2007). Mas, se a própria noção de performance e os seus limites não são definíveis, como definir então uma Antropologia da Performance?

\section{Análise crítica do "performance turn" - Estudos da performance}

Apesar da difícil legitimação dos estudos da performance promovidos por departamentos ou centros de investigação, só no início dos anos 90 é que a Antropologia da Performance se começa a estabelecer em alguns departamentos de antropologia, embora para o caso português os estudos da performance tenham tido sempre uma recepção adiada (Seiça Salgado, 2013). No entanto, a viragem performativa nos estudos antropológicos dá-se por volta das décadas de 70 e 80 quando Victor Turner, ao lado de Richard Schechner lançam as sementes que criariam raízes quando se avizinharia um novo campo disciplinar - os Performance Studies.

Schechner integrava a «minoria artística» que formava a vanguarda novaiorquina da «Performance Art», pertinentemente resenhada por Rosalee Goldberg (2007), como acima descrevi. As reflecções de Schechner provinham da sua experiencia em 
teatro de vanguarda, sendo que algumas das suas primeiras propostas resultaram de experiências de teatro de rua e protestos contra a Guerra do Vietname, e de um diálogo fecundo com o teórico Victor Turner, um antropólogo escocês que iniciou a sua cruzada por entre as sinuosas veredas dos rituais e dos dramas sociais nos anos 50, com trabalho de campo entre os Ndembo (Dawsey, 2011).

Num ensaio publicado em 1986, Turner declara que "durante anos, eu sonhei com uma antropologia libertada" (Turner, 1986в: 72). Ou seja, uma antropologia livre dos preconceitos que a caracterizam e distinguem enquanto género literário, ostentando assim uma crítica à disciplina e à sucessiva desumanização dos sujeitos de estudo antropológico, entendidos como estando condicionados por "pressões, forças ou variáveis sociais, culturais e psicológicas" (Raposo, 2013: 13). Assim sendo, Turner afastou-se deste modelo no seu trabalho de campo, procurando analisar os sistemas sociais enquanto processos condicionados por princípios de acção e regras de costume incompatíveis (Raposo, 2013).

Explorando as relações entre ritual e teatro, Turner apercebeu-se que o ritual estaria encrustado ao processo social e que esse seria também performativo (Schechner, 1986). As suas conviç̧ões quanto ao carácter dinâmico das relações sociais, fizeram-no notar uma forma no processo do tempo social que era essencialmente dramática. Turner elabora, deste modo, um modelo de Drama Social baseando-se no arquétipo dos ritos de passagem de Van Gennep (Turner, 2008), ou seja, separação (fase preliminar), margem (fase liminar) e agregação (fase pós-liminar) (Van Gennep, 1878).

Refere o autor que uma das características mais marcantes na vida social dos Ndembo era a propensão ao conflito, conflito que se manifestava "em episódios de irrupção pública de tensão" (Turner, 2008: 28), ou seja, «dramas sociais». Explicitando melhor o termo, para Turner os dramas são:

Composições literárias que contam uma história, geralmente sobre conflito humano, através do diálogo e ação, e são performatizadas por atores e apresentadas a um público, cuja natureza e grau de envolvimento e participação variam de cultura para cultura (Turner, 1986a: 27).

Assim, procurou formular uma «forma processual do drama», reforçando que os dramas sociais podem ser isolados para investigação em qualquer sociedade, independentemente da sua dimensão e complexidade (Turner, 2008). Acrescenta 
ainda que no «drama social» a ênfase recai sobre a lealdade e obrigação, possibilitando que o curso dos acontecimentos possa adquirir uma qualidade trágica (Turner, 2008)

De acordo com o pensamento de Turner, eventos menos dramáticos preparam gradualmente o terreno para confrontos de maior dimensão, sendo que "os distúrbios do normal e do regular muitas vezes nos oferecem um maior insight sobre o normal do que o estudo directo" (Turner, 2008: 30), fazendo com que a estrutura se revele através da anti-estrutura ou contra-estrutura. De acordo com o autor, o conflito permite que os aspectos essenciais da sociedade, encobertos pelo costume e hábito, ganhem proporções assustadoras, para além de obrigar os sujeitos a tomar posições. Assim, os «dramas sociais» apresentam-se como "unidades de processo anarmónico ou desarmônico que surgem em situações de conflito" (Turner, 2008: 33), evidenciando-se, deste modo, a intrínseca relação entre «ritual»e «conflito».

Estes tais «dramas sociais» geralmente representam sequências de eventos sociais que têm uma estrutura tecida de acordo com os fios do tempo, mas "a estrutura de fases do drama social não é produto do instinto, e sim de modelos e metáforas que os atores carregam nas suas cabeças" (Turner, 2008: 31). Mas é certo que, como destaca Calvanti, "a ideia orgânica e propriamente dramatúrgica do drama social (...), no qual uma fase gesta a outra desde dentro, as ações respondendo-se umas às outras e desdobrando-se em novas ações, trouxe certamente a temporalidade processual como uma dimensão central para a apreensão do dinamismo da vida social (Calvanti, 2013: 418).

Explicitando a afirmação da autora, Turner, baseando-se nas fases dos ritos de passagem do Van Gennep (1978) apresenta-nos um quadro faseado do «drama social ${ }^{2}$, sendo a sua proposta marcada por "uma autonomização da fase liminar"

2 O primeiro momento do «drama social» trata-se do reconhecimento de uma crise, manifestando tensões e posterior ruptura das relações sociais formais (Turner, 2008). Após irromperem as tensões latentes à relações e interações sociais, dá-se o segundo momento do «drama social», ou seja a ampliação da crise, envolvendo cada vez mais actores, pautando-se por um momento de inflexão, perigo e suspense que permite revelar um verdadeiro estado de coisas (Turner, 2008).

A terceira fase do «drama social» trata-se da acção correctiva. Nesta fase as técnicas pragmáticas, bem como a acção simbólica são expressadas em pleno, pois "aqui, a sociedade, grupos, comunidade (...), está em seu momento mais "auto-consciente" e pode 
(Godinho, 2014в: 12). Argumenta o autor que todas as crises públicas apresentam características liminares, fazendo referência a um liminar entre fases relativamente estáveis do processo social.

O conceito de liminaridade associa-se à noção de «margem», estado que se refere a indivíduos que estão numa fase de "passagem" de uma posição de status ou lugar para outro (Van Gennep, 1978). Assim, os «dramas sociais» caracterizam-se pela liminaridade, permitindo aos actores sociais estarem à «margem» da sociedade e criando condições para os indivíduos ou grupos representarem papéis correspondentes a uma posição invertida do status que geralmente possuem na hierarquia da «estrutura social» (Turner, 2008). Dentro do modelo de liminariedade proposto por Turner, destaca-se o sentimento de «communitas», ou seja, uma relação entre indivíduos que não estão segmentados numa função e posição social, mas que se defrontam uns com os outros criando uma espécie de «anti-estrutura», um modelo alternativo de organização social. Neste sentido, surge a liminaridade na communitas, porque esta se situa à margem da estrutura social e é composta por momentos extraordinários como os «dramas sociais» ou «ritos de passagem» que, precisamente, interrompem o fluxo normal do quotidiano (Turner, 1974).

É a noção de liminaridade que Turner aponta como um elemento que diferencia os «dramas sociais» e «ritos de passagem» nos seus contextos socioculturais particulares, de outros fenómenos culturais, como por exemplo as actividades ligadas ao campo artístico nas «sociedades complexas», modelo este que será reconfigurado com a introdução do conceito de «liminóide» que o fará repensar a sua teoria do «ritual» a partir da noção de «performance» e das propostas de Schechner.

A teoria de Schechner passou pela criação de um novo modelo de análise antropológica de eventos performáticos, como o é possível entender através das

atingir a clareza de pensamento de uma pessoa encurralada, lutando pela vida" (Turner, 2008: 36). A própria fase correctiva ou regenerativa possui traços liminares, fornecendo "uma réplica e uma crítica distanciada dos eventos que compuseram e levaram à crise" (Turner, 2008: 36).

Finalmente, a última fase do «drama social» é o rearranjo ou cisão,sendo que é nesta fase que, pautada pela reintegração do grupo social perturbado ou reconhecimento e legitimação social do cisma irreparável entre as partes do conflito, é permitido fazer o balanço da situação (Turner, 2008). 
suas duas principais obras: Between Antropology and Theater (1985) e Performance Theory (1988). Focando-se no «teatro» e na relação entre o performer e a audiência, Schechner desenvolve uma análise comparativa entre performances teatrais de vários países com o objectivo de acentuar a distinção entre «ritual»e «teatro» ou, neste caso, a ausência desta. O argumento do autor prende-se com a ideia de que não existe uma distinção entre «ritual» e «teatro», uma vez que ambos são categorias de uma mesma natureza: performances (Alves da Silva, 2005). E as performances, de acordo com Schechner:

Marcam identidades, dobram o tempo, remodulam e adornam o corpo, e contam estórias. Performances - de arte, rituais, ou da vida cotidiana - são "comportamentos restaurados", "comportamentos duas vezes experienciados", ações realizadas para as quais as pessoas treinam e ensaiam (Schechner, 2006: 2).

De acordo com Schechner, qualquer actividade da vida humana pode ser entendida enquanto performance e todas as actividades da vida pública são performances colectivas (desde a política, às demonstrações populares, até formas de protesto como as revoluções ou a guerra civil), uma vez que as performances existem apenas enquanto acções, interacções e relações, ou seja, a arte performática ao fazer ou mostrar algo executa uma acção:

Uma pintura "acontece" em seu objeto físico; um livro acontece nas palavras. Mas uma performance acontece enquanto ação, interação, $e$ relação. Deste modo, uma pintura ou um romance podem ser performativos ou serem analisados "enquanto" performances. A performance não está "em" nada, mas "entre (Schechner, 2006: 4).

O autor define ainda que todas as acções se constroem a partir de comportamentos previamente experienciados, sendo que também as performances advêm destas "porções de comportamento restaurado" (Schechner, 2006: 4). Assim, a inovação ou originalidade de um evento resulta do modo como as parcelas de comportamento podem ser organizadas ou restauradas. Schechner argumenta ainda que a performance, bem como a vida diária, consiste em repetição, evidenciando o modo como esta se assemelha ao ritual, defendendo que separar «arte» de «ritual» se torna algo particularmente difícil (Schechner, 2006).

Deste modo, a contribuição de Schechner recai sobre uma visão da performance que compreende uma continuidade que vai do «ritual» ao «teatro» e do «teatro» ao «ritual». De modo exemplificativo, na sua obra Between Theater and 
Anthropology (1985), Schechner atribui o modelo dos «ritos de passagem» de Van Gennep (1978) ao padrão processual da performance cénica, na qual o período preliminar equivale à fase de ensaios, onde se remove o habitus, o liminar à performance em si e o pós-liminar ao relaxamento após a $2^{a}$ fase, quando se regressa ao quotidiano (Schechner, 1985). Deste modo, evidencia o aspecto ritualizado do «teatro» e a performatividade do «ritual», rompendo com uma interpretação perpetuada por Durkheim que reconhecia a oposição binária e dicotómica entre «ritual» e «teatro», classificados no sentido de «sagrado/profano» (Schechner, 1985), de acordo com o modelo de Turner.

Mas, resultando de uma contaminação mútua, Turner embebe das teorias de Schecnher e, assim, "o drama da estrutura e antiestrutura termina no palco da cultura" (Turner, 1974:6):

O teatro é uma dessas muitas herdeiras do grande sistema multifacetado que chamamos de "ritual tribal", que abrange idéias e imagens do cosmos e do caos, interdigitando palhaços e suas folias com deuses e suas solenidades, e fazendo uso de todos os códigos sensoriais para produzir sinfonias para além da música (Turner, 1986c: 184).

Analisando a performance cultural nas sociedades complexas, Turner conclui que as performances podem ser consideradas dentro das situações «extraordinárias» ou momentos de interrupção da ordem social. Mas, enquanto Schechner emprega a noção de «ritual» num sentido mais lato e afastado da tal dicotomia sagrado/profano, Turner opta por manter essa distinção ao avançar com o conceito de «performance cultural» (Alves da Silva, 2005). Assim, o antropólogo estabelece uma distinção entre «performances sociais», como os ritos de passagem e dramas sociais, e «performances estéticas» ou «culturais», como os dramas estéticoteatrais. Embora se manifestem inúmeras diferenças entre o modelo de Schechner e o modelo proposto por Turner, ambos entendem os rituais e dramas sociais como uma espécie de «metateatro», ou seja, um espaço simbólico de representação da realidade social que recorre à inversão de papéis que propiciam uma experiência singular que é simultaneamente reflexiva:

A forma estética do teatro é inerente à própria vida sociocultural, mas o caráter reflexivo e terapêutico do teatro, cujas origens remontam à fase reparadora do drama social, precisa recorrer às fontes do poder frequentemente inibidas na vida do modo indicativo da sociedade. A criação de um espaço liminar separado, quase-sagrado, permite uma busca de tais fontes. Uma fonte desse excessivo meta-poder é certamente o próprio corpo 
liberado e disciplinado, com seus múltiplos recursos não explorados de prazer, dor e expressão (Turner, 1986c: 184).

Turner considera assim que os dramas sociais possuem também fontes de forma estética, o que inclui o drama de palco. Trata-se de um entendimento da performance teatral enquanto «drama social», momento onde as estruturas de experiência grupal são copiadas, desmembradas, rememoradas e tornadas significativas (Turner, 1986c).

Mas, ao passo que germinariam os frutos deste campo de estudos, o interesse pela performance abalroava as fronteiras da disciplina, evocando-se desde logo uma distinção entre teatro e metateatro: enquanto Turner se focava nos momentos de excepção, sobraçando o metateatro da vida social, Goffman (1959) e Debord (1967) autopsiavam a performance quotidiana e, respectivamente.

$\mathrm{Na}$ década de 50, em França, assistiu-se a um interesse sociológico pela performance por parte de alguns teóricos, entre os quais se destaca o sociólogo George Gurvitch que, em 1956, publica a sua Sociologia do Teatro (1956), na qual não só aborda a dimensão social do teatro, como destaca a relevância da performance no mundo social (Carlson, 2011). A par desta nova orientação em França, vários teóricos nos E.U.A. desenvolveram ideias semelhantes, entre os quais se destaca o sociólogo Erving Goffman que, na sua obra $A$ Representação do Eu na Vida Cotidiana (1959), constrói um modelo de estudo sociológico que tem como referência o teatro - a dramaturgia, como forma de interpretar a interação social. Na acepção Goffmaniana o «mundo social» é um «palco» e todos os indivíduos na ordem da interacção são actores que desempenham papéis preestabelecidos socialmente de acordo com a expectativa da «plateia». Deste modo, é mobilizada uma «fachada social» enquanto equipamento expressivo empregue pelos indivíduos durante essa representação (Goffman, 2011).

Goffman distingue assim «aparência», os "estímulos que funcionam no momento para nos revelar o status social do ator" (Goffman, 2011: 31), de «maneira», "os estímulos que funcionam no momento para nos informar sobre o papel de interação que o ator espera desempenhar na situação que se aproxima" (Goffman, 2011: 31). Refere ainda que, no campo da fachada, quase sempre esperamos uma compatibilidade entre «aparência» e «maneira». Contudo, Goffman demonstra-nos que estas podem ser mutuamente contraditórias: 
Quando um ator que parece ser de posição mais elevada que sua plateia age de maneira inesperadamente igualitária, íntima ou humilde, ou quando um ator vestido com o traje de uma alta posição se apresenta a um indivíduo de condição ainda mais elevada. Além da esperada compatibilidade entre aparência e maneira, esperamos naturalmente certa coerência entre ambiente, aparência e maneira (Goffman, 2011: 32).

Com isto, a contribuição Goffmaniana evidencia as manifestações performativas da vida quotidiana no campo da fachada, sugerindo que a "fachada torna-se uma "representação coletiva" e um fato, por direito próprio" (Goffman, 2011: 34). Mas se, de acordo com Goffman, o mundo social é um palco, então pode-se considerar que estamos inseridos numa «sociedade do espectáculo» na acepção do filósofo francês Guy Debord (Debord, 2003).

Nesta época marcada por uma instrumentalização da arte tendo em vista fins de subversão e resistência e pela emancipação da «performance art», o filósofo e cineasta revolucionário Guy Debord, que liderava a Internacional Situacionista, um grupo de intelectuais saídos da decomposição do surrealismo e dadaísmo que criticavam a sociedade daquela época e defendiam uma «arte» separada da «vida», publica, em 1967, a obra «A Sociedade do Espectáculo» ${ }^{3}$, que haveria de influenciar os movimentos de «maio de $68^{4} \gg$ (Dias, 2008).

\footnotetext{
${ }^{3}$ Em 1973, Debord converte a sua «Sociedade do Espectáculo» num filme ou, poder-se-ia dizer anti-filme com o mesmo nome. No filme, que serve de suporte à teoria do livro, é marcado pela dissociação entre imagem e som e, denunciando um cinema político, apresentou-se como uma forma de crítica à sociedade vigente. Disponível em: < https://www.youtube.com/watch?v=q0A]66Rb-10> [Consultado a 11 de Julho de 2016].

${ }^{4} \mathrm{O}$ ano de 1968 é marcado por inúmeras transformações sociais e políticas, nomeadamente dentro do movimento estudantil em França. Em maio de 1968 vários estudantes de uma universidade dos arredores de Paris realizaram protestos reclamando mudanças políticas, culturais e sociais. A 3 de maio as autoridades encerram a Universidade de Sorbonne e os estudantes passam a reclamar a renúncia do então presidente Charles de Gaulle. 0 movimento passa a ter o apoio operário que, aproveitando a conjuntura, realizou a greve mais longa da história francesa. O movimento estudantil motivou outros movimentos revolucionários noutros países como na Alemanha ou em Itália, onde os estudantes criticavam a hegemonia de uma ideologia católica no que dizia respeito a temas como o aborto e divórcio. Nos Estados Unidos, assinalava-se uma época marcada pelo movimento negro e o assassinato de Martin Luther King, bem como por movimentações estudantis contra Guerra do Vietname. Também na América Latina, os jovens protestavam contra a ditadura então estabelecida, bem como no México se acendiam protestos por uma maior abertura política (Dias, 2008).
} 
Em «A Sociedade do Espectáculo», Debord defende que a vida em sociedade é um espectáculo, ou seja, uma representação de e sobre a realidade, promovida por um sistema capitalista que cria ambientes de encenação (Debord, 2003):

Toda a vida das sociedades nas quais reinam as condições modernas de produção se anuncia como uma imensa acumulação de espectáculos. Tudo o que era directamente vivido se esvai na fumaça da representação (Debord, 2003:13).

A perspectiva debordiana, fazendo uso da metáfora teatral, abdica do seu conteúdo metafórico ao interpretar o espectáculo não como um modo de representação do mundo, mas como algo inerente ao próprio mundo:

O espectáculo é ao mesmo tempo parte da sociedade, a própria sociedade e o seu instrumento de unificação. Enquanto parte da sociedade, o espectáculo concentra todo o olhar e toda a consciência. Por ser algo separado, é o foco do olhar iludido e da falsa consciência, a unificação que realiza não é outra coisa senão a linguagem oficial da separação generalizada (Debord, 2003:14).

Assim, o espectáculo torna-se a visão cristalizada do mundo e a afirmação da vida social enquanto aparência, sendo entendida pelo filósofo enquanto uma consequência da modernização das condições de produção, que culmina com uma perda da unidade do mundo, resultante da alienação do homem face aquilo que produz (Debord, 2003). Como refere Debord, "o espectáculo é o capital a um grau de acumulação que se torna imagem" (Debord, 2003: 27), assim esta acumulação de capital resulta na criação de um mundo, no qual a interação entre os indivíduos é mediada por imagens, transformando tudo o que é experienciado em representação (Idem). E de acordo com esta perspectiva, o espectáculo resulta numa auto-representação do mundo que se sobrepõe ao próprio mundo real. Esta espectacularização do mundo manifesta-se nos média, na propaganda, nas interações pessoais ou nas actividades culturais enquadradas numa narrativa totalizante que legitima e é produzida pelo próprio sistema que reúne as condições de uma sociedade perfeita para ser governada, no sentido em que o espectáculo, sendo o «foco do olhar iludido», dispensa a verdade e oculta formas de dominação política (Debord, 2003). Deste modo, a contribuição debordiana, evidenciada numa perspectiva marxista, passa por uma crítica ao fetichismo da mercadoria e à alienação, refletindo, tal como Goffman, uma ideia do mundo como palco onde os indivíduos assumem e descartam papéis, bem como perpetua uma interpretação do espetáculo como expressão de uma vida falsificada, retomando a mais antiga crítica 
platónica relativa ao teatro ${ }^{5}$.

Também dentro desta perspectiva goffmaniana/debordiana, é possível enquadrar a teorização de Georges Balandier acerca da encenação do poder político. Um dos maiores contributos do antropólogo francês é precisamente o conceito de «teatrocracia do poder», emanado da sua obra O poder em cena, publicada em 1980. Para o antropólogo a «teatrocracia» trata-se de um dispositivo de poder que visa produzir efeitos ilusórios como no teatro, onde "o grande ator político comanda o real através do imaginário" (Balandier, 1982:6). A «teatrocracia» governa a partir dos bastidores e está por detrás de todas as organizações de poder:

Um tribunal teatral para todas as manifestações da existência social, notadamente as do poder: os atores políticos devem pagar seu tributo quotidiano à teatralidade (Balandier, 1982:6).

Na perspectiva de Balandier é através da encenação que o poder político obtém a subordinação, pois um poder que se exerça através da força manifesta-se débil no sentido em que não necessita de legitimação e reconhecimento pela classe dominada, por sua vez irá encontrar sempre uma maior força de revolta. Deste modo, para que o poder se veja legitimado e permaneça é necessário dar-Ihe uma aparência diferente do que este é na sua essência (Balandier, 1982).

Atendendo a que o imaginário ilumina o fenómeno político, o controlo social mantém-se através de uma produção de imagens e manutenção de símbolos num quadro cerimonial onde o governante se apresenta enquanto um actor político com associação a uma ritualização de conquista e legitimação de poder, pois apenas numa representação idealizada o governante poderá corresponder às características míticas que os subordinados desejam encontrar neste. A subordinação permite-se então através da sacralização dos símbolos, de cerimónias e espectáculos e das dramatizações dos agentes do poder (Balandier, 1982). Assim, a verdade do poder localiza-se:

No substrato das grandes mitologias mais do que no saber produzido pela sua própria ciência (Balandier, 1982:5).

\footnotetext{
${ }^{5}$ A recusa ao teatro para Platão prende-se com o facto de esse "fazer passar as ficções por realidade" (Monteiro, 2010: 78), se descentrar do orador para ter a função de agradar ao espectador, e ter uma estreita relação com as emoções, isto é, por permitir que se abram "emocionantes brechas por onde a razão se pode perder" (Ibidem).
} 
Deste modo, o «mito do herói» é o exemplo máximo da teatralidade política, uma vez que reclama uma dimensão mais «espectacular» do que rotineira, obtendo assim um grande poder de mobilização. Poder este que se vê amplamente reconhecido durante as crises políticas, quando alcança o auge da sua força dramática (Balandier, 1982).

Balandier acrescenta ainda que nos governos democráticos as potencialidades dramáticas parecem menos intensas quando comparadas com regimes totalitaristas, assentes mais visivelmente na representação política na qual o mito da unidade sobressai. No entanto, mesmo em democracias, essa representação pode observada nas eleições, onde as técnicas de publicidade fornecem meios relevantes na encenação da «dramaturgia democrática». De modo a obter subordinação, o poder representa-se como a própria imagem da sociedade que governa de modo a devolver uma imagem idealizada dessa mesma sociedade. 0 Estado transforma-se então em «espectáculo», num teatro de ilusões (Balandier, 1982).

Posto isto, a maior contribuição de Balandier para a discussão em torno da performance alicerça-se na ideia de uma construção teatral do social e das estruturas políticas, no sentido em que as relações sociais, enquanto mecanismos específicos para manter as estruturas do poder, e as diferenças hierárquicas entre os governantes e os governados se estruturam e reforçam por meio de performances (Balandier, 1982).

Já no final dos anos de 1980 , observou-se uma mudança de paradigma em relação ao conceito de antropologia da performance, em grande parte impulsionada por Johannes Fabian que, no seu artigo Power and Performance (1990), defende um conceito de antropologia da performance mais radical relativamente às contribuições de Victor Turner. Se Turner se focava mais na forma dramática ou performativa das erupções sociais e culturais, concebendo-as de um modo discursivo, Fabian defendia que o conhecimento cultural está muito mais relacionado com a prática do que com o discurso, sendo apenas possível de ser compreendido, não através da narração, mas da sua encenação, defendendo assim uma etnografia com maior ênfase na participação, no conhecimento corporal e na experiência vivida, o que levou a que a ênfase de Turner nas metáforas do drama e do teatro perdessem um pouco a sua centralidade (Carlson, 2011). Este retorno ao 
«corpo» vir-se-ia também a destacar no trabalho de Eugénio Barba, um influente diretor de teatro experimental do final do século $X X$, que se viria a afastar da antropologia da performance.

Eugénio Barba enquanto diretor teatral decidiu sediar a sua companhia experimental na cidade dinamarquesa de Holstebro, na qual foi desenvolvendo produções e pesquisas num campo ao qual chamou «Antropologia Teatral», sendo que em 1979, decide criar o ISTA, International School of Theatre Anthropology (Carlson, 2011). No entanto, a antropologia teatral de Barba, ao contrário dos Estudos da Performance, não se foca no estudo das tradições performativas no seu contexto sócio-cultural e muito menos utiliza uma lente teórica performativa na análise dos fenómenos humanos, mas trata-se antes do estudo de um «comportamento cénico pré-expressivo» no qual assentariam os diferentes géneros, papéis e tradições culturais, procurando assim por princípios comuns de performance (Barba, 1995).

Empreendendo a sua antropologia teatral face a uma antropologia que "não procura descobrir leis, mas estudar regras de comportamento" (Barba, 1995: 7), Barba defende a existência de princípios similares em representações diferentes e procura compreender em que consiste a linguagem do actor:

A antropologia teatral é, portanto, o estudo do comportamento sociocultural e fisiológico do ser humano numa situação de representação (Barba, 1995:8).

Partindo de uma análise comprativa entre o teatro oriental e o teatro ocidental, Eugénio Barba defende que existe um nível de organização comum a todos os actores, entendido como pré-expressivo. Assim, o director teatral procura definir como campo da Antropologia Teatral o modo como se torna a energia do actor viva cenicamente, ou seja, "como o actor pode tornar-se uma presença que atrai imediatamente a atenção do espectador" (Barba, 1995: 188). Este substrato préexpressivo, acrescenta, está incluído no nível de expressão e está na raiz de todas as técnicas de representação, pelo que os princípios que governam a préexpressividade seriam universais (Barba, 1995).

Assim, para Barba, cada performance implica um conjunto de princípios préexpressivos, tais como equilíbrio, oposições e equivalências, que orientam a conduta corporal e a energia vital e que compõem o «bios» e a «presença» extracotidiana do actor em cena, permitindo ao corpo dos actores transcender a 
sua função quotidiana enquanto meros comunicadores de mensagens (Barba, 1995). Interessado na utilização que os teatros e os actores teatrais fazem desses princípios pré-expressivos, Barba ambicionava "prestar um serviço tanto para o ator ocidental quanto para o ator oriental, para os que têm uma tradição codificada, e para os que sofrem pela falta de uma." (Barba, 1995: 9).

No entanto, uma das críticas mais inflacionadas ao trabalho de Barba, como aponta Johnson, prende-se precisamente com esta comparação entre o teatro ocidental e oriental. Acusado de expressar uma atitude orientalista face ao teatro nãoocidental, Barba denuncia também uma visão essencialista e mística do Outro asiático (Johnson, 2015), e, poderei acrescentar, perpetua uma visão ocidentalizada do teatro ocidental ${ }^{6}$. Para além disto, a sua visão estruturalista, ao procurar princípios universais entre o teatro oriental e ocidental, não tem em consideração a reciprocidade entre actores provenientes de culturas colonizadoras e actores provenientes ou formados dentro de culturas colonizadas (Johnson, 2015). Contudo, a atitude pouco reflexiva de Barba face ao seu contexto de estudo, não invalida a sua enorme contribuição para os estudos antropológicos, caracterizada por um grande enfoque no processo ao invés do «produto teatral», nos «actores teatrais» em detrimento dos «actores sociais» e no retorno ao «corpo», à experiência vivida e à interação sujeito/objecto.

Posto isto, a viragem performativa nas ciências sociais pode ser entendida então a partir da vertente dramatúrgica evidenciada nas contribuições de Eugénio Barba, Guy Debord, Victor Turner, Richard Schechner ou Erving Goffman, que procurava compreender a globalidade da prática performática. E embora este interesse perdurasse, rapidamente se dá um desdobramento para o campo da linguística no âmbito das etnografias da fala e dos estudos das performances narrativas (Raposo, 2013).

\footnotetext{
${ }^{6}$ Refira-se como exemplo algumas citações: "quando os actores-bailarinos ocidentais querem ser enérgicos (...), frequentemente começam a se mover no espaço com tremenda vitalidade (...). Os actores orientais podem tornar-se mais cansados quase sem se mover" (Barba, 13). Ou então: "os actores ocidentais contemporâneos não possuem um repertório orgânico de «conselhos» para proporcionar apoio e orientação. Têm como ponto de partida geralmente um texto ou as indicações de um director de teatro" (Barba, 1995: 8). Enquanto o actor oriental "possui uma base orgânica e bem testada de conselho absoluto, isto é, regras de arte que codificam um estilo de representação fechado" (Barba, 1995: 8). Ou ainda afirmações como "Quase todos os mestres do teatro oriental ordenam a seus discípulos que não se preocupem com outros géneros de representação" (Barba, 1995: 8).
} 
Foram vários os teóricos que procuraram por uma articulação entre a antropologia e performance para além da teatralidade. Surgem então linguistas como John Austin que exploram os chamados actos de fala (speech acts), entendidos como declarações performativas que, para além de enunciarem coisas, fazem coisas (Austin, 1990).

Criticando o antigo pressuposto filosófico, que entendia que a função de uma declaração seria apenas descrever um estado de coisas ou declarar um acto, Austin toma como exemplo uma cerimónia de casamento para nos demonstrar que, quando o noivo diz diante do altar «Aceito, esta mulher como minha legítima esposa» não está a descrever um acto, mas sim a praticá-lo. Querendo com isto afirmar que, ao dizer «Aceito», o noivo não está a relatar um casamento, mas a casar-se (Austin, 1990). A este tipo de proferimento, o autor dá o nome de sentença performativa ou, de forma abreviada, «performativo», evidenciando assim a performatividade da fala:

Evidentemente que este nome é derivado do verbo inglês to perform, verbo correlato do substantivo "ação", e indica que ao se emitir o proferimento está - se realizando uma ação (Austin, 1990: 25).

Acrescenta ainda que o performativo tem de implicar sempre uma circunstância, pois este será sempre vazio ou nulo se "dito por um ator no palco, ou se introduzido em um poema, ou falado em um solilóquio" (Austin, 1990: 32). Tomando ainda como exemplo o acto do matrimónio, se o noivo ainda está casado com alguém vivo, que é são e de quem não se divorciou, nesse caso o acto é considerado nulo (de acordo com a religião cristã). Contudo, ainda que um acto seja considerado nulo não significa que nada tenha sido feito, pois através dele, neste exemplo, pode-se ter cometido bigamia. Deste modo, Austin assume que «Dizer é fazer» e que a fala preenche também uma função performativa (Austin, 1990).

Já Noam Chomsky ao distinguir competência (o conhecimento que o falante-ouvinte tem da sua língua) e desempenho (o uso real da língua em situações concretas) (Chomsky, 1970: 6), aproxima-nos de uma noção de performance linguística como modo de pensar a relação entre os actores sociais e as expressões por estes utilizadas. Neste sentido, "qualquer testemunho de fala natural demonstrará inúmeros falsos arranques, desvios à regra, mudanças de plano a meio do caminho, 
entre outros" (Chomsky, 1970: 6), que Chomsky considerará a execução performativa da fala. Para além destes lapsos, hesitações e desordens linguísticas que passam a ser entendidos num sentido performativo por contraste à estrutura organizadora da língua, investigações mais recentes demonstram-nos como os recursos simbólicos e metalinguísticos também podem preencher uma função performativa (Langdon, 2013).

Esther Langdon numa abordagem pioneira à antropologia e performance em Portugal, nas suas pesquisas sobre do uso ritual de yajé e as narrativas xamânicas, demonstra-nos como os "mecanismos poéticos, dramatizações corporais e vocais, e estratégias dialógicas constroem a presença do mundo invisível" (Langdon, 2013: 22), evidenciando-nos, não só como a performance das narrativas preenche uma função estética na construção da experiência dos xamãs e da plateia com o mundo dos espíritos, mas se apresenta como uma importante contribuição na transmissão do conhecimento (Langdon, 2013). Posto isto, arrisco considerar que o grande contributo da área linguística para os estudos da performance passa pelo reconhecimento da função performativa da fala, bem como um entendimento sobre as narrativas que reconhece a sua expressão performativa e estética ao estabelecerem recursos simbólicos e mecanismos metafóricos e metonímicos como forma de dramatizar os eventos.

\section{Considerações finais}

Os Estudos da Performance permitem-nos traçar uma mundividência sustentada numa «sociedade do espectáculo» que é marcada por uma performance do mundo social em que toda a actividade humana é performativa, inclusive os recursos linguísticos, e as relações sociais são mediadas por performances que procuram as suas manifestações no campo da «fachada» (Schechner, 2006; Goffman, 2011) e contribuem para legitimar as estruturas do poder através de uma «teatrocracia» que sustenta o fosso entre governantes e governados (Balandier, 1982). Uma sociedade onde irrompem episódios de conflito e de tensão - «dramas sociais» (incluindo fontes de forma estética) -, que se apresentam como um «metateatro», um espaço simbólico de representação da realidade social que permite aos actores sociais estarem à «margem» da sociedade e recorre à inversão de papéis, tornando-se um espaço simultaneamente reflexivo onde as estruturas de experiência grupal são copiadas, desmembradas e re-significadas (Turner, 1986) e 
onde se estabelece uma forte relação entre performance e política.

Posto isto, o edifício teórico apresentado procura reafirmar a antropologia da performance como uma «terra de todos», uma manta de retalhos complexa que abrange as mais diversas perspectivas e posicionamentos e que só pode ser compreendida através de uma abordagem interdisciplinar e politicamente comprometida que passa por uma compreensão do mundo dentro de uma simbiose que cruza performance e política, na qual se torna relevante analisar a relação que esta estabelece com as formas de subversão e resistência ao poder.

\section{Referências bibliográficas}

Alves da Silva, Rubens (2005). "Entre artes e ciências: a noção de performance e drama no campo das ciências sociais", Em Horizontes Antropológicos, Porto Alegre, ano 11 , n. 24 , p. 35-65, jul./dez.

Artaud, Antonin (1983), O Teatro e seu Duplo, São Paulo: Martins Fontes, Coleção OPUS 86.

Austin, John L. (1990), Quando dizer é fazer, Porto Alegre: Artes Médicas.

Balandier, Georges (1982), "O drama", Em O poder em cena, Brasília: Editora Universidade de Brasília (Colecção Pensamento Político), [Trad. De Luiz Caldas de Moura].

Barba, Eugénio (1995), A arte secreta do actor: dicionário de antropologia teatral, Brasil: Unicamp.

Bourdieu, P. (1989), "Introdução a uma sociologia reflexiva", Em Poder Simbólico, Lisboa, Difel, pp. 17-58.

Calvanti, Maria (2013), Drama, ritual e performance em Victor Turner, Em Sociologia e antropología, Rio de janeiro, v.03, no 06, pp. 411 -440, novembro.

Carlson, Marvin (2011), "O Entrelaçamento dos Estudos Modernos da Performance e as Correntes Atuais", Em Antropologia Revista Brasileira de Estudos da Presença, Porto Alegre, v. 1 , n. 1, p. 164-188, jan./jun. Disponível em $<$ http://www.seer.ufrgs.br/presenca>. 
Cedeño, Janneth (2010), "Arte y política. Entre propaganda y resistência", Anuario colombiano de historia social y de la cultura, vol. 37, n.o 2 - 2010, ISSN 01202456, Bogotá - Colombia, págs. 221-243.

Chomsky, N. (1970), "Preliminares Metodologicos", Em Aspectos de la teoría de la sintaxis, Madrid: Aguilar.

Dawsey, John C. (2007), "Sismologia da performance: Ritual, drama e play na teoria antropológica", Em Revista de antropologia, São Paulo, USP, V. 50 No 2.

Dawsey, John C. (2011), "Schechner, teatro e antropologia", Em Cadernos de Campo, São Paulo, n.20, pp.1-360. Disponível em < https://performancesculturais.emac.ufg.br/up/378/o/dawsey.pdf> [Consultado a 29 de Junho de 2016].

Debord, Guy (2003), A Sociedade do Espetáculo, São Paulo: Coletivo Periferia.

Dias, Paulo Vergílio (2008). "40 Anos do Maio de 68: A Sociedade do Espetáculo, de Guy Debord", Em Anais do XIX Encontro Regional de História: Poder, Violência e Exclusão. ANPUH/SP - USP. São Paulo, 08 a 12 de setembro. Disponível em <http://www.anpuhsp.org.br/sp/downloads/CD\%20XIX/PDF/Autores\%20e\%20Arti gos/Paulo\%20Vergilio\%20Marques\%20Dias.pdf>[Consultado a 11 de Julho de 2016].

Fradique, Teresa (2014), "For years, I have dreamed of a liberated Anthropology", Em Paula Godinho, coord. Antropologia e Performance - Agir, Atuar, Exibir. Castro Verde: 100Luz, pp. 9-24.

Giovanni, Julia Ruiz Di (2015), "Artes de abrir espaço. Apontamentos para a análise de práticas em trânsito entre arte e ativismo", em Cadernos de Arte e Antropologia, Vol. 4, No 2 | -1, 13-27.

Godinho, Paula (2014a). Antropologia e Performance - Agir, Atuar, Exibir. Castro Verde: 100Luz, pp. 9-24.

Godinho, Paula (2014B). "Agir, atuar, exibir. Antropologia e Performance, uma introdução", in Paula Godinho, coord. Antropologia e Performance - Agir, Atuar, 
Exibir. Castro Verde: 100Luz, pp. 9-24.

Goffman, Erving (2011 [1959]), A Representação do Eu na Vida Cotidiana. 14a ed., Editora Vozes, Petrópolis, pp. 1-40.

Goldberg, Roselee (2007 [1978]), A Arte da Performance. Do Futurismo ao Presente, Lisboa: Orfeu Negro.

Johnson, Anne (2015), "Navegando las Tierras de Nadie - Richard Schechner y Eugenio Barba", Em Diário de Campo, Ano 2, no6-7, Janeiro - Abril. Disponível em <https://www.researchgate.net/publication/283089710_Performances_politicos_y_ sociologia_cultural> [Consultado a 06 de Agosto de 2016].

Langdon, Esther Jean (2013), "A viagem à casa das onças: narrativas sobre experiências extraordinárias", in Paulo Raposo, et al. (orgs.), A Terra do Não Lugar: Diálogos entre Antropologia e Performance, Florianópolis, Editora da Universidade Federal de Santa Catarina (EdUFSC).

Monteiro, Paulo Filipe (2010), "Suspeitas sobre o espectáculo", Em Drama e Comunicação, Coimbra: Imprensa da Universidade de Coimbra.

Oliveira, Patrícia (2011). Política e arte: desvios, leituras e emergências. Dissertação (Mestrado em Ciência Política e Relações Internacionais) - Faculdade de Ciências Sociais e Humanas, Universidade Nova de Lisboa, Portugal, 122 f.

Quilici, Cassiano (2004), "o corpo sem órgãos ou a dança às avessas", em Antonin Artaud: teatro e ritual, São Paulo: Annablume, FAPESP.

Raposo, Paulo (2013), "No performance's land? Interrogações contemporâneas para uma teoria da performance", in Paulo Raposo, et al. (orgs.), A Terra do Não Lugar: Diálogos entre Antropologia e Performance, Florianópolis, Editora da Universidade Federal de Santa Catarina (EdUFSC).

Schechner, Richard (1985), Between Theater and Anthropology, Philadelphia: University of Pennsylvania Press.

Schechner, Richard (1986), "Victor Turner's Last Adventure", Em TURNER, Victor 
(1986), The Anthropology of Performance, NY: PAJ Publications.

Schechner, Richard (2005), "Approaches", Em Performance Theory (Edição ampliada de "Essays on Performance Teory", 1977, 1988), NY \& London, Routledge, pp. 1-34.

Schechner, Richard (2006), "What is performance?", em Performance studies: an introduccion, second edition. New York \& London: Routledge, p. 28-51 [Tradução de R. L. Almeida].

Seiça Salgado, Ricardo (2013), "O inacabado caminho até a antropologia da performance em Portugal", Baldio Habitado, 30 de Abril. Disponível em <https://baldiohabitado.wordpress.com/antropologia-anthropology/> [consultado a 02 de Julho de 2016]

Turner, Victor (1974), O processo ritual: estrutura e anti-estrutura. Petrópolis: Vozes, [1969]. pp. 9-13; 116-160.

Turner, Victor (1986a), "Images and Reflections: Ritual, Drama, Carnival, Film, and Spectacle in Cultural Performance", Em The Anthropology of Performance, NY, PAJ Publications.

Turner, Victor (1986B). The anthropology of performance. In: TURNER, Victor. The anthropology of performance. New York: PAJ Publications, 1987. p. 72-98.

Turner, Victor (1986c), An Essay in the Anthropology of Experience. (Tradução de DAWSEY, John. "Victor Turner e antropologia da experiência", Em Cadernos de Campo, USP, n.13, 205 (p. 163-185).

Turner, Victor (2008), "Dramas sociais e metáforas rituais", Em Drama, campos e metáforas, Niterói: EdUFF. Disponível em $<$ http://www.do.ufgd.edu.br/mariojunior/arquivos/dramas_campos_metaforas.pdf $>$ [Consultado a 19 de Maio de 2015].

Van Gennep, Arnold (1978), Os ritos de passagem (Apresentação de Roberto da Matta), Petrópolis: Vozes, p. 9-33. 